\title{
Simplified Intraoperative Goal-Directed Therapy Using the FloTrac/Vigileo System: An Analysis of Its Usefulness and Safety
}

\author{
Kenji Ito, Miho Ito, Aki Ando, Yuki Sakuma, Toshiyasu Suzuki \\ Department of Anesthesiology, Tokai University School of Medicine, Kanagawa, Japan \\ Email: itokenji@is.icc.u-tokai.ac.jp
}

How to cite this paper: Ito, K., Ito, M., Ando, A., Sakuma, Y. and Suzuki, T. (2017) Simplified Intraoperative Goal-Directed Therapy Using the FloTrac/Vigileo System: An Analysis of Its Usefulness and Safety. Open Journal of Anesthesiology, 7, 1-14. http://dx.doi.org/10.4236/ojanes.2017.71001

Received: October 13, 2016

Accepted: January 21, 2017

Published: January 24, 2017

Copyright (c) 2017 by authors and Scientific Research Publishing Inc. This work is licensed under the Creative Commons Attribution International License (CC BY 4.0).

http://creativecommons.org/licenses/by/4.0/

\begin{abstract}
Purpose: We investigated whether the simplified intraoperative Goal-Directed Therapy (GDT) could improve the factors affecting medical costs, and contribute in standardizing intraoperative fluid management. Methods: The enrolled patients underwent esophagectomy, pancreatoduodenectomy, or aortic stent grafting in 2012, and between March 2013 and October 2014. We conducted a comparison study on the effects of GDT, between the beforeGDT historical control group $(n=100)$ and GDT group $(n=100)$. The hemodynamic indices used for control group patients were conventional: Blood pressure, heart rate, and urine output. For GDT group, additionally, we used stroke volume variation (SVV) and stroke volume index (SVI). The primary outcomes were the length of intensive care unit (ICU) stay and hospital stay (LOS). Regression analysis was used to identify factors affecting LOS. The secondary outcomes were the albumin use, the fluid amount administered, and the variation in the fluid administration rate. Results: The control and GDT groups comprised 96 and 99 patients, respectively. The patient characteristics were similar. The length of ICU stay was significantly shorter $(2.1 \pm 2.1$ days vs. $2.8 \pm 1.9$ days, $P=0.0009)$ and LOS was shorter but without statistical significance ( $24.5 \pm 17.7$ days vs. $27.7 \pm 20.1$ days, $P=0.21)$ in the GDT group than in the control group. The fluid amount administered and the presence/ absence of albumin use were factors affecting LOS. The variation of the fluid administration rate was significantly lower in the GDT group. Conclusion: The simplified GDT may contribute to the improvement of medical economics and standardize the fluid management.
\end{abstract}

\section{Keywords}

FloTrac/Vigileo, Fluid Management, Goal-Directed Therapy, Patient Outcome 


\section{Introduction}

Goal-directed therapy (GDT) is a patient management strategy based on a predefined protocol, in which target values are set for hemodynamic indices in order to optimize patients' hemodynamics. In 2001, a randomized controlled trial (RCT) in patients with severe sepsis demonstrated that the mortality rate was significantly reduced in patients receiving GDT [1]. This approach has also been applied to the management of surgical patients under general anesthesia, and it has been reported that GDT may improve patient outcomes by reducing the length of hospital stay (LOS) and the incidence of complications [2] [3] [4]. Moreover, a meta-analysis showed that postoperative outcomes can be improved by GDT, based on cardiac output measured with a hemodynamic monitoring device [5]. The intraoperative execution of standardized hemodynamic management based on a predefined algorithm prevents hypoperfusion and an excess of fluid administration, and improves patient outcomes. It has been suggested that outcomes are improved, especially in patients with a systemic comorbidity [3]. Fluid loading based on the varied experiences of anesthesiologists may lead to excessive loading of sodium ions or fluid. This excessive loading may increase the incidence of postoperative complications [6]; therefore, the standardization of intraoperative fluid management prevents complications. Postoperative GDT for patient care also reportedly reduces the incidence of complications [4]; therefore, it is preferable for medical professionals involved in perioperative care to share their common knowledge about GDT.

However, the reported algorithms of intraoperative GDT are considerably complicated [2] [3] [4]. For patients without any comorbid systemic diseases who are undergoing elective routine surgery, GDT needs to be simplified as much as possible.

The FloTrac/Vigileo system (Edwards Lifesciences, Irvine, CA) detects pulse waves through a peripheral arterial catheter and calculates the stroke volume (SV). From this algorithm, cardiac output (CO) can be calculated, and the percentage of respiratory fluctuations in SV (stroke volume variation: SVV) can be used as an index of fluid responsiveness [7] [8]. Measurement with this system is relatively less invasive and easy to use. Its algorithm has been repeatedly upgraded so that it does not largely depend on the values of peripheral vascular resistance. It has also been reported that the cardiac output measured by the system is correlated with the value measured by the pulmonary arterial catheter [9]. We could introduce the system for intraoperative patient management with no difficulty because of the simplicity, easy preparation and placement for measurement, and because of the low incidence of complications.

In large-scale or prolonged surgery, it is often difficult to maintain a balanced fluid volume. Fluid management can be standardized by administering fluid or vasopressors, based on the hemodynamic indices obtained by monitoring. The usefulness of GDT using the FloTrac/Vigileo system has been reported [10] [11]; we investigated the effects of GDT on the length of intensive care unit (ICU) stay and LOS, especially in terms of the effects under the Japanese health care system. 
Furthermore, we analyzed the data of all patients to identify the intraoperative factors affecting the length of hospital stay. In previous studies, the effects of GDT introduction on the albumin dosage and the total amount of fluid administered during surgery have not been closely examined. Hence, we also determined whether the introduction of simplified GDT could reduce the albumin dosage, and lead to the standardization of fluid management.

\section{Materials and Methods}

Before initiation, this study was approved by the ethics committee of Tokai University Hospital (Kanagawa, Japan) and registered at University Hospital Medical Information Network (UMIN) Center (UMIN 000012809). The inclusion criteria were patients with American Society of Anesthesiologists (ASA) Class I to III status, based on the ASA Physical Status classification, and patients who were scheduled to undergo esophagectomy, pancreatoduodenectomy, or aortic stent grafting. In November 2012, GDT was introduced into our hospital, and the study patients were enrolled from March 2013 to October 2014 after the ethics committee approval. Historical patients data who had undergone surgery before its introduction in 2012 were collected for the control group. Written consent from each participant in the GDT group in this study was obtained. Each type of surgical procedure was performed by the same surgeons, and anesthesia was administered by anesthesiologists with 5 years or more of experience. All procedures were performed under general anesthesia, for which no specific protocols were set for maintenance anesthesia, postoperative analgesic therapy, and so forth.

\subsection{Induction and Maintenance of Anesthesia}

No preanesthetic medication was administered. After admitting the patients in the operating room, they were attached to monitors to obtain an electrocardiogram, noninvasive blood pressure measurements, and percutaneous oxygen saturation measurement. In patients requiring postoperative epidural anesthesia, an epidural puncture was performed to place a catheter. General anesthesia was then induced with propofol and remifentanil. After muscle relaxation was achieved with rocuronium, we conducted intratracheal intubation. The initial respiratory conditions were a tidal volume of $10 \mathrm{~mL} / \mathrm{kg}$ and a respiratory rate of 10 breaths per minute. The positive end-expiratory pressure was set at $0 \mathrm{~cm}$ $\mathrm{H}_{2} \mathrm{O}$. After anesthetic induction, an arterial line was placed in the radial artery. After confirming that the FloTrac/Vigileo system was displaying arterial pressure waves, monitoring was started. In the esophagectomies, after the chest was opened, we increased the fraction of inspired oxygen, but we did not change the respiratory conditions in principle.

Anesthesia was maintained with inhalation anesthesia or with a continuous infusion of propofol and remifentanil, as well as oxygen and air. Fentanyl and rocuronium were intermittently administered, as needed. The bispectral index value was adjusted to $40-60$, and the end-tidal carbon dioxide concentration 
was maintained at $30-40 \mathrm{mmHg}$.

Patients undergoing esophageal surgery returned to the ICU under sedation and with intubation. Patients undergoing pancreatoduodenectomy or aortic stent grafting were extubated in the operating room and returned to the ICU. GDT was continued until a patient left the operating room in the case of esophagectomy, or until extubation in the case of pancreatoduodenectomy or aortic stent grafting.

\subsection{Circulatory Management}

Patients in the control group received conventional management, based on their blood pressure, heart rate, and urine output. The amount of fluid administration and the use of colloid solutions and vasopressors were not restricted but left to the discretion of the attending anesthesiologists.

Patients in the GDT group received hemodynamic management, based on indices obtained from the FloTrac/Vigileo system. Stroke volume (SV), which can be measured by the FloTrac/Vigileo system, and stroke volume variation (SVV), which reflects respiratory fluctuation in SV, were used as hemodynamic indices. SVV is a dynamic index and more useful as an index of fluid responsiveness than static indices such as central venous pressure. Some previous studies reported that use of SVV as an index of fluid management during operations improved the prognosis after high-risk surgeries [9] [12]. Stroke volume index (SVI) is a value that is not affected by patients' physiques, and was used as an index of blood flow. The algorithm for the management of the GDT group is shown in Figure 1. In the GDT group, the initial rate of crystalloid administration was set at $8 \mathrm{~mL} / \mathrm{kg} / \mathrm{h}$. Based on the stroke volume variation (SVV) and SVI obtained from FloTrac/Vigileo system, the target values were set at an SVV of

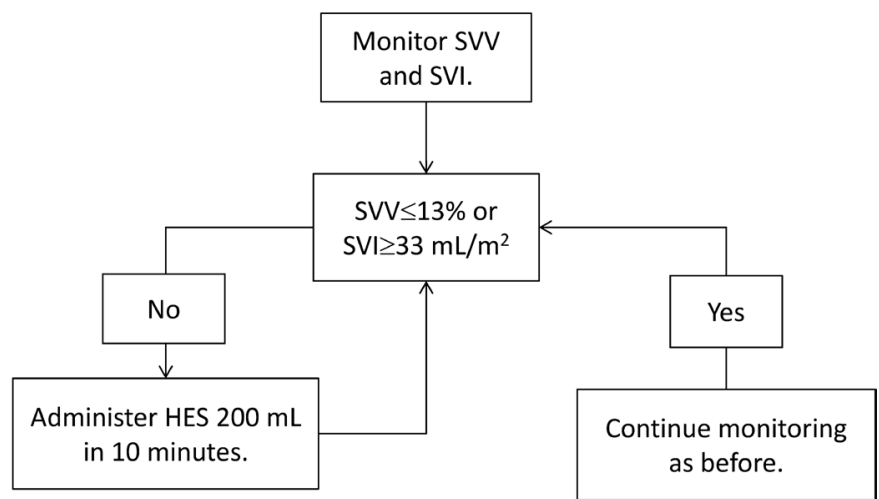

Figure 1. Goal-directed therapy protocol at our facility: The initial fluid administration is initiated with crystalloid solutions at a dose of $8 \mathrm{~mL} / \mathrm{kg} / \mathrm{h}$. The stroke volume variation (SVV) and stroke volume index (SVI) are obtained from the FloTrac/Vigileo system. When the system provides an SVV of exceeding $13 \%$, or an SVI of less than $33 \mathrm{~mL} / \mathrm{m}^{2}$, $200 \mathrm{~mL}$ of $6 \%$ hydroxyethyl starch (HES) is administered over 10 minutes. If the parameters are not improved after the initial fluid loading, a second bolus is administered. If there is still no improvement, ephedrine or phenylephrine is administered. Albumin preparations are administered when the dosage of HES exceeds $20 \mathrm{~mL} / \mathrm{kg}$ or when the amount of blood loss exceeds $1000 \mathrm{~mL}$. 
$13 \%$ or lower and an SVI of $33 \mathrm{~mL} / \mathrm{beat} / \mathrm{m}^{2}$ or higher. When increased values for SVV were observed at the time of pancreatoduodenectomy, aortic stent grafting, and esophagectomy without thoracotomy, and when decreased values for SVI were observed at the time of esophagectomy involving thoracotomy, $200 \mathrm{~mL}$ of $6 \%$ hydroxyethyl starch (HES; Hespander; Fresenius Kabi Japan, Tokyo, Japan) or Voluven (Fresenius Kabi, Tokyo, Japan) was infused over 10 minutes. If the bolus improved the SVV or SVI and cardiac index (CI), careful observation of the parameters was continued. When no improvement was observed, the bolus injection was repeated. When the SVI did not improve, despite a decreased SVV, the administration of ephedrine or phenylephrine was considered. When hypotension persisted, despite several bolus injections and the administration of vasopressors, dobutamine was continuously infused. When SVI showed the normal value, but SVV increased, vasodilation was assumed and a vasoconstrictive agent was administered. Albumin was administered when more than $20 \mathrm{~mL} / \mathrm{kg}$ of HES was administered or blood loss exceeded $1000 \mathrm{~mL}$. Administering more than $20 \mathrm{~mL} / \mathrm{kg}$ of HES is not reimbursable in Japanese health care system.

Our target for urine output was $0.5 \mathrm{~mL} / \mathrm{kg} / \mathrm{h}$ or more. When decreased urine output seemed to be attributable to hypovolemia, HES was administered by bolus. When hypotension appeared to be the cause of decreased urine output, a bolus HES injection or vasopressors were administered. When patients did not respond to the treatment, furosemide was administered. Blood samples were collected intermittently during surgery, and blood was transfused to maintain hemoglobin levels at $8 \mathrm{~g} / \mathrm{dL}$.

\subsection{Outcome Measures}

The primary outcomes were the length of ICU stay and the total LOS. In addition, intraoperative factors affecting the total LOS were investigated. The secondary outcomes were the amount of albumin administered, the ratio of the patients who used albumin, the total amount of fluid administered, the amount of crystalloid solutions, the variations in these parameters, and the frequency of vasopressor use during surgery. As for safety outcomes, serum creatinine and blood urea nitrogen (BUN) levels were measured before and after surgery.

\subsection{Exclusion Criteria}

Patients were excluded for the following reasons: age less than 18 years, severe arrhythmia, atrial fibrillation, severe aortic regurgitation, or severe heart, kidney, or liver dysfunction. Patients who did not return to the ICU after surgery because of reasons such as changes in surgical procedures, or who developed atrial fibrillation during surgery, or who had a history of allergic reactions to HES were also excluded.

\subsection{Statistical Analysis}

Statistical analyses were performed using SAS software, version 9.2. (SAS Institute, Cary, NC, USA). The continuous variables were expressed as the mean \pm 
the standard deviation or as the median (range). The binary variables were expressed as a percentage. Intergroup comparison of the continuous variables was performed by using the t-test. When the variables deviated from normal distribution, they were log-transformed to approximate normal distribution for analysis. Moreover, on the continuous variables, an $\mathrm{f}$-test was performed to compare the variations in the patient care methods to assess the effect of GDT on the method. Intergroup comparison of the binary variables was performed by Fisher's exact probability test. The ordered categorical variables (i.e., with three or more categories) were analyzed with the Cochran-Mantel-Haenszel correlation test. A paired t-test was performed to compare the mean values before and after surgery. To identify intraoperative factors affecting the total LOS, simple linear regression analysis was performed in all patients. All analyses were performed with two-tailed $\mathrm{P}$ values. In addition, multiple linear regression analyses were conducted to obtain the optimal model that predicts the LOS, and to identify the factors that predict the LOS. A P-value of less than 0.05 indicated a statistically significant difference.

\section{Results}

Of the eligible patients, three patients were excluded from the control group, of whom two were not returned to the ICU because of changes in surgical procedures and one because of developing atrial fibrillation during surgery. In the GDT group, one patient who developed atrial fibrillation during surgery was excluded. As a result, this study included 96 patients in the control group (44 with esophageal cancer, 32 with pancreatic cancer, and 20 undergoing stent-graft placement) and 99 patients in the GDT group (42 with esophageal cancer, 37 with pancreatic cancer, and 20 undergoing stent-graft placement). The patients' characteristics are shown in Table 1 . No differences were observed in patient characteristics, including operative and anesthesia time. None of the patients received dobutamine or furosemide.

The length of ICU stay and LOS are shown in Figure 2. The length of ICU stay was significantly shorter in the GDT group than in the control group $(2.1 \pm$ 2.1 days vs. $2.8 \pm 1.9$ days, $\mathrm{P}=0.0009$ ). The LOS was shorter in the GDT group than in the control group, but without statistical significance ( $24.5 \pm 17.7$ days vs. $27.7 \pm 20.1$ days, $\mathrm{P}=0.21$ ). In all patients, a simple linear regression analysis was performed to identify intraoperative factors affecting the total length of hospital stay. The results are shown in Table 2. Surgical procedures were identified as the most prominent factor affecting the length of hospital stay. Among the factors related to anesthetic management, albumin use $(\mathrm{r}=0.497, \mathrm{P}<0.001)$ and the total amount of fluid administration $(\mathrm{r}=0.494, \mathrm{P}<0.001)$ showed a significant correlation with LOS. In addition, multiple linear regression analyses were performed to obtain the optimal model that predicts the LOS.

The factors of the optimal model included the type of surgery, the presence/ absence of albumin use, and the dosage of HES (Table 3). The multiple regression coefficient was 0.75 , and the adjusted $\mathrm{R} 2$ was 0.5533 . The presence/absence 
of GDT was not a factor in either simple or multiple linear regression analyses. The albumin dosage and the rate of albumin use are shown in Figure 3. The albumin dosage was significantly lower in the GDT group than the control group $(126 \pm 206 \mathrm{~mL}$ vs. $261 \pm 283 \mathrm{~mL}, \mathrm{P}=0.0002)$, and the ratio of patients who used

Table 1. The patients' characteristics.

\begin{tabular}{cccc}
\hline & Control $(\mathrm{n}=96)$ & GDT $(\mathrm{n}=99)$ & P value \\
\hline Age (years) & $69.0 \pm 8.2$ & $68.9 \pm 8.1$ & NS \\
Gender (M/F) & $23 / 73$ & $29 / 70$ & NS \\
Height (cm) & $162.3 \pm 8.7$ & $161.5 \pm 8.9$ & NS \\
Weight (kg) & $56.5 \pm 10.1$ & $57.1 \pm 13.1$ & NS \\
ASA-PS (1/2/3/4) & $17 / 66 / 11 / 1$ & $7 / 84 / 8 / 0$ & NS \\
Anesthesia time (min) & $437 \pm 153$ & $421 \pm 177$ & NS \\
Operative time (min) & $371 \pm 152$ & $356 \pm 178$ & NS \\
Esophagectomy & 44 & 42 & - \\
Pancreatoduodenectomy & 32 & 37 & - \\
TAA/AAA stent-grafting & 20 & 20 & - \\
\hline
\end{tabular}

The data are expressed as the mean \pm the standard deviation. An unpaired t-test was performed on age, weight, height, operative time, and anesthesia time. Fisher's exact test was performed on gender, and Cochrane-Mantel-Haenszel test was performed on ASA-PS. ASA-PS: American Society of Anesthesiologists Physical Status; GDT: goal-directed therapy; TAA: thoracic aortic aneurysm; AAA: abdominal aortic aneurysm.

Table 2. Factors affecting the total length of hospital stay: Results of simple linear regression analysis.

\begin{tabular}{ccc}
\hline Items & Correlation coefficient $(\mathrm{r})$ & P value \\
\hline Operative time $(\mathrm{m} / 60)$ & 0.632 & $<0.0001$ \\
Volume of crystalloid solutions (total, mL/100) & 0.402 & $<0.0001$ \\
Colloid dosage (total, $\mathrm{mL} / 100)$ & 0.429 & $<0.0001$ \\
Albumin (administered = 1, not administered $=0)$ & 0.497 & $<0.0001$ \\
Total amount of fluid (mL/100) & 0.494 & $<0.0001$ \\
Amount of blood loss (Log 10) & 0.480 & $<0.0001$ \\
In-out balance (mL/1000) & 0.387 & $<0.0001$ \\
Ephedrine dosage (mg) & 0.180 & 0.0120 \\
Surgical procedure types & 0.203 & 0.0045 \\
Preoperative creatinine level (Log 10) & 0.172 & 0.0168 \\
Sumber of ephedrine doses administered (times) & 0.727 & $<0.0001$ \\
\hline
\end{tabular}


Table 3. Multiple regression model.

\begin{tabular}{ccc}
\hline Variable & Estimated regression coefficient & Pvalue \\
\hline Intercept & 2.906 & $<0.0001$ \\
HES/100 & 0.022 & 0.0718 \\
Alb (use: 1 , no use: 0) & 0.380 & 0.0017 \\
Surgery: esophagectomy/aortic stent grafting & $1.236^{*}$ & $<0.0001$ \\
Surgery: pancreatoduodenectomy & $1.236^{*}$ & $<0.0001$ \\
Multiple correlation coefficient: & 0.750 & \\
Adjusted R2 & 0.553 & \\
\hline
\end{tabular}

The group of response variables obtained from this model equation is the base 2 logarithm of the length of hospital stay. For example, when the result of calculation is 5, the expected length of hospital stay is 25 days, i.e., 32 days. ${ }^{*}$ The coefficients of esophagectomy and pancreatoduodenectomy when the coefficient of aortic stent grafting is assumed to be 1 .

\begin{tabular}{lcccc}
\hline & Control $(\mathrm{n}=96)$ & GDT $(\mathrm{n}=99)$ & P value & $\begin{array}{c}\text { F test } \\
\text { (Homoscedasticity) }\end{array}$ \\
\hline $\begin{array}{l}\text { ICU length of stay } \\
\text { (day) }\end{array}$ & $2.8 \pm 1.9$ & $2.1 \pm 2.1$ & 0.0009 & 0.929 \\
$\begin{array}{l}\text { Length of stay after an } \\
\text { operation (days) }\end{array}$ & $27.7 \pm 20.1$ & $24.5 \pm 17.7$ & 0.2070 & 0.964 \\
\hline
\end{tabular}
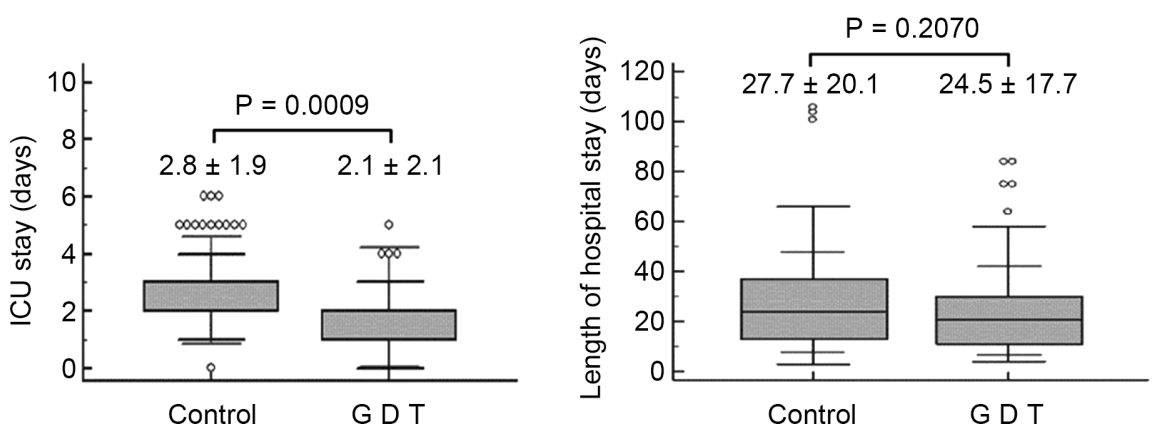

Figure 2. The length of intensive care unit stay and hospital stay. The data are expressed as number of days.

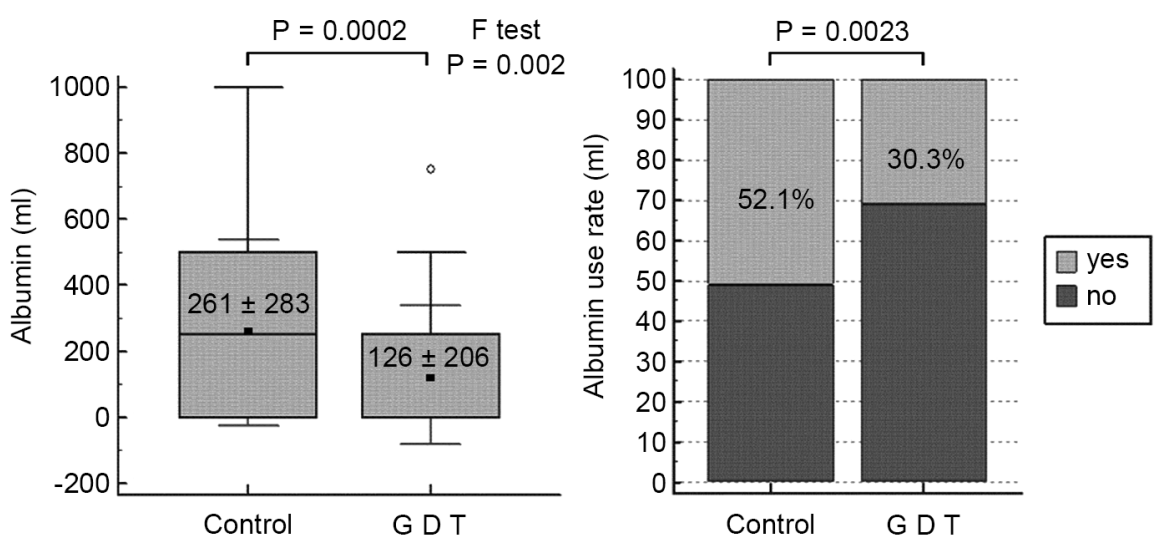

Figure 3. The total amount and rate of albumin administration. The amount is shown as the mean \pm standard deviation. 
albumin was significantly lower in the GDT group than in the control group ( $30.3 \%$ vs. $52.1 \%, \mathrm{P}=0.0023)$. As for intraoperative fluid management, the infusion rate and amount of crystalloid and total fluid administered, the in-out balance, and the frequency of ephedrine and phenylephrine administration are shown in Table 4. The amount of crystalloid solutions and total fluid administered was smaller in the GDT group than in the control group $(3454 \pm 1575 \mathrm{~mL}$ vs. $3724 \pm 1459 \mathrm{~mL}$ and $4254 \pm 1965 \mathrm{~mL}$ vs. $4654 \pm 1784 \mathrm{~mL}$, respectively), and the variation in the infusion rates was significantly smaller in the GDT group than in the control group $(9.2 \pm 2.7 \mathrm{~mL} / \mathrm{h}$ vs. $9.8 \pm 4.3 \mathrm{~mL} / \mathrm{h}, \mathrm{P}<0.0001$ and 11.2 $\pm 3.2 \mathrm{~mL} / \mathrm{h}$ vs. $12.0 \pm 4.7 \mathrm{~mL} / \mathrm{h}, \mathrm{P}=0.0001$, respectively). The variation in the in-out balance was significantly smaller in the GDT group than in the control group (7.4 $\pm 2.8 \mathrm{~mL} / \mathrm{h}$ vs. $8.2 \pm 4.0 \mathrm{~mL} / \mathrm{h}, \mathrm{P}=0.0006)$. For ephedrine and phenylephrine use, the frequency of their administration and the variability of the administration frequency per patient were significantly smaller in the GDT group. As for the safety outcomes, the serum creatinine and BUN levels before and after surgery are shown in Table 5 . Neither group showed any abnormal increases in serum creatinine and BUN levels after surgery. Moreover, no patient in either group required renal replacement therapy after surgery.

Table 4. Intraoperative management.

\begin{tabular}{|c|c|c|c|c|}
\hline & $\begin{array}{l}\text { Control } \\
(\mathrm{n}=96)\end{array}$ & $\begin{array}{c}\text { GDT } \\
(\mathrm{n}=99)\end{array}$ & $P$ value & $\begin{array}{c}\text { F test } \\
\text { (Equality of variance) }\end{array}$ \\
\hline Crystalloids (mL) & $3724 \pm 1459$ & $3454 \pm 1575$ & $\mathrm{NS}^{*}$ & NS \\
\hline Crystalloids (mL/kg/h) & $9.8 \pm 4.3$ & $9.2 \pm 2.7$ & $\mathrm{NS}^{*}$ & $<0.0001$ \\
\hline Colloids (mL) & $669 \pm 394$ & $674 \pm 537$ & $\mathrm{NS}^{*}$ & 0.0027 \\
\hline Total amount of fluid (mL) & $4654 \pm 1784$ & $4254 \pm 1965$ & $\mathrm{NS}^{*}$ & NS \\
\hline Total amount of fluid $(\mathrm{mL} / \mathrm{kg} / \mathrm{h})$ & $12.0 \pm 4.7$ & $11.2 \pm 3.2$ & $\mathrm{NS}^{*}$ & 0.0001 \\
\hline Blood loss (mL) & $548 \pm 403$ & $469 \pm 386$ & $\mathrm{NS}^{*}$ & NS \\
\hline $\begin{array}{l}\text { Urinary output }(\mathrm{mL}) \\
\text { (Log urinary output) }\end{array}$ & $\begin{array}{l}1112 \pm 824 \\
(829 \pm 0.8)\end{array}$ & $\begin{array}{c}1085 \pm 1010 \\
(710 \pm 1.0)\end{array}$ & $\mathrm{NS}^{* *}$ & NS \\
\hline $\begin{array}{l}\text { Urinary output }(\mathrm{mL} / \mathrm{kg} / \mathrm{h}) \\
\text { (Log urinary output }(\mathrm{mL} / \mathrm{kg} / \mathrm{h})\end{array}$ & $\begin{array}{c}2.6 \pm 1.7 \\
(2.2 \pm 0.6)\end{array}$ & $\begin{array}{c}2.6 \pm 1.9 \\
(2.0 \pm 0.8)\end{array}$ & $\mathrm{NS}^{* *}$ & NS \\
\hline In-Out Balance (mL) & $3090 \pm 1314$ & $2724 \pm 1336$ & $\mathrm{NS}^{*}$ & NS \\
\hline In-Out Balance $(\mathrm{mL} / \mathrm{kg} / \mathrm{h})$ & $8.2 \pm 4.0$ & $7.4 \pm 2.8$ & $\mathrm{NS}^{*}$ & 0.0006 \\
\hline Ephedrine (times) & $4.4 \pm 3.2$ & $3.4 \pm 2.5$ & $0.0156^{*}$ & 0.0137 \\
\hline Phenylephrine (times) & $2.5 \pm 4.9$ & $1.4 \pm 3.3$ & $0.0396^{*}$ & 0.0001 \\
\hline
\end{tabular}

The data are expressed as the mean \pm the standard deviation. As for fluid administration, the amount $(\mathrm{mL})$ and infusion rates $(\mathrm{mL} / \mathrm{kg} / \mathrm{h})$ are provided for crystalloid solutions and total fluid administration. The amount and rate $(\mathrm{mL} / \mathrm{kg} / \mathrm{h})$ are similarly provided for the in-out balance. A single dose of ephedrine and phenylephrine is $4 \mathrm{mg}$ and $0.1 \mathrm{mg}$, respectively; the number of doses administered is provided. HES, hydroxyethyl starch. ${ }^{\star}$ Based on the Student t-test. ${ }^{* *}$ Based on the $\mathrm{t}$-test with log transformation. GDT: goal-directed therapy. 
Table 5. Preoperative and postoperative creatinine and BUN.

\begin{tabular}{ccc}
\hline & Control $(\mathrm{n}=96)$ & GDT $(\mathrm{n}=99)$ \\
\hline Cr (Pre-op) & $0.8 \pm 0.3$ & $0.8 \pm 0.2$ \\
Cr (Post-op) & $0.70 \pm 0.23$ & $0.77 \pm 0.27$ \\
P value & 0.0136 & NS \\
\hline BUN (Pre-op) & Control $(\mathrm{n}=96)$ & GDT (n $=99)$ \\
BUN (Post-op) & $15.6 \pm 6.3$ & $16.3 \pm 4.7$ \\
P value & $13.4 \pm 3.9$ & $15.8 \pm 5.3$ \\
\hline
\end{tabular}

Renal replacement therapy was not administered in either group. BUN: blood urea nitrogen; Cr: creatinine; GDT: goal-directed therapy.

\section{Discussion}

Many reports indicate that intraoperative management based on GDT improves patient outcomes [2] [3] [4]. GDT reduces the incidence of postoperative complications and mortality; therefore, the benefit of GDT seems to be established. Moreover, comparable effects of GDT using solely the FloTrac/Vigileo system to its effects using other hemodynamic monitors have been demonstrated, and this therapy has been reported as simple and safe [10] [11]. We also previously reported in a small series (before the present study) that GDT contributes to the standardization of fluid management [13] and a reduction in surgical costs [14]. In these studies, the usefulness of GDT has been confirmed, as reflected by a reduced LOS and incidence of complications. Our present study also revealed that the length of ICU stay was significantly reduced in the GDT group, and the LOS tended to be shorter (although not significantly) in the GDT group. Based on our algorithm, the initial administration rate of maintenance fluid was 8 $\mathrm{mL} / \mathrm{kg} / \mathrm{h}$ of crystalloid solution. The overall maintenance rate of fluid administration consequently was $9.2 \pm 2.7 \mathrm{~mL} / \mathrm{kg} / \mathrm{h}$, which was higher than the rate reported by a study conducted in the United States [15]. Modifying our rate setting may further contribute to the reduction in the LOS. This is an important issue that merits further investigation. Lilot et al. [15] conducted a survey on the amount of intraoperative fluid administration in the United States. In their survey, they found that the amount varies greatly among attending anesthesiologists. Moreover, the amount varies greatly, based on the type of surgery. Based on these findings, Lilot et al. proposed that providing consistent healthcare service requires correcting such a variation. In our present study, the variation in the infusion rates of the crystalloid solution was significantly smaller in the GDT group than in the control group, and the variation in the overall infusion rate of fluid administration was also smaller in the former group. Moreover, the amount of crystalloid solution and total fluid administration tended to be smaller in the GDT group. Specifying the administration rate of the maintenance fluid and target value setting for parameters may have contributed to the standardiza- 
tion of fluid management. The results of the present study showed no difference between the GDT group and the control group as to the total amount of fluid administered. An adequate amount of fluid was thought to be administered with appropriate timing in the GDT group through the standardization of fluid management based on fluid responsiveness and the index of blood flow.

In particular, regression analysis performed in all patients suggested that albumin use affected the LOS. To our knowledge, there has been no report to date focusing in detail on the effects of GDT on intraoperative albumin dosage or standardization of fluid management [16]. Albumin has been invariably used during surgery; however, a controlled study in the field of intensive care failed to demonstrate the superiority of albumin over physiologic saline on the outcomes of patients with head trauma [16]. In Japan in 2015, guidelines were issued for the proper use of albumin, based on evidence [17]. According to the guidelines, albumin is contraindicated in patients with head trauma, and it usually should not be used for bleeding. Although the current guidelines do not prohibit the intraoperative use of albumin, we believe that its use will be restricted in the future. Moreover, albumin is more expensive than HES in Japan (US \$400 - \$580 vs. US $\$ 70$ - $\$ 80$ ). In addition, since the Diagnosis Procedure Combination system was introduced in Japan in 2003, the medical cost for patient management has been calculated as part of the cost for comprehensive medicine. At present, surgical costs are not included in this process; however, if a reduction in the cost of anesthesia becomes a topic of discussion, further restriction on albumin use may result. It was suggested that the dosage of HES preparation might affect the LOS as well. An increase in SVV or decrease in SVI can occur upon bleeding. If this occurs, an adequate cardiac output is maintained through a bolus administration of HES. In our view, the most valuable finding of the present study is that the albumin dosage can be reduced through bolus administration of HES to maintain adequate cardiac output.

Furthermore, the frequency of ephedrine and phenylephrine administration was significantly lower in the GDT group. This finding may be the result of adequate cardiac output maintained by an adequate bolus administration of HES. Although application of GDT was not reflected directly in the LOS, it might indirectly contribute to a significant reduction of the length of ICU stay or tendency of shortened LOS: The optimized timing of fluid administration reduced the use of vasopressors, which had been administered at the anesthetist's discretion, and bolus administration of HES reduced the dosage of albumin.

To assess the safety of GDT in the present study, changes between the preand post-surgery serum creatinine and BUN levels, and the frequency of the administration of renal replacement therapy were analyzed. Neither of the levels fluctuated, and none of the patients required the therapy. Therefore, our protocol appears safe. The GDT protocol of 2012 in the Surviving Sepsis Campaign, which was proposed after verification by Rivers et al. in 2001 [1], recommends that HES should not be used in sepsis cases with an evidence level of Class 1B [18]. This recommendation is attributed to reports demonstrating that HES use 
causes hypoglycemia and renal dysfunction and increases mortality within 90 days [19] [20] [21]. There are also reports that HES use does not affect renal function or mortality in surgical patients [22]. In the present study, the total amount of fluid administration tended to be smaller in the GDT group; therefore, clinicians must be careful about the effects of HES on renal function. Hydroxyethyl starch was used in the control and GDT groups in our study, but there was no abnormal elevation in the serum creatinine or BUN level. No patient required dialysis. Renal dysfunction and increased mortality due to HES were observed in studies conducted in patients with severe sepsis [19] [20] [21]. Thus, we believe that, as long as HES doses remain within the standard clinical range, the risk of renal dysfunction is small in general surgical patients without any comorbid systemic diseases.

The limitations of the present study include the following: 1) this study was conducted at a single facility; 2) the control group was retrospectively assessed; 3) although the operations were performed by the same surgeons, their surgical techniques may have improved with time; and 4) the criteria for ICU and hospital discharge were not specified and postoperative complications were not investigated. Furthermore, because of the characteristics of the FloTrac/Vigileo system, measurements are inaccurate in patients with severe arrhythmia, atrial fibrillation, or severe aortic regurgitation. As Secher et al. also indicate [23], there is always a possibility that measurements obtained from the FloTrac/Vigileo system are affected by a patient's posture and other factors, and thus may not reflect the actual condition. Moreover, when urgent blood loss is compensated for by HES, the SVV reportedly does not quickly respond to blood volume changes [24].

We introduced simplified GDT for intraoperative management. The hemodynamic parameters we used were only SVV, SVI, and CI but the present study suggested that GDT can reduce the length of ICU stay, and likely reduces the LOS. It has also been suggested that GDT can reduce the intraoperative albumin dosage and standardize intraoperative management. These results raise the possibility that simplified GDT may improve patient outcomes and reduce medical costs. To generate evidence, large-scale RCTs on GDT are needed in the future.

\section{Acknowledgements}

We owe much to Mr. Furukawa of Biostatistical Research Corporation for statistical analysis. For English translation we thank Honyaku Center Inc. This study was financially supported by Edwards Lifesciences.

\section{Declaration}

Part of the data included in the present study was published in the reference 13 (JJSCA 2015; 35: 573-578) and reference 14 (JJSCA 2015; 35: 159-165).

\section{Conflict of Interest Statement}

As a research team, Kenji Ito received the study fund for this study from Ed- 
wards Lifesciences Limited. Miho Ito, Aki Ando, Yuki Sakuma, and Toshiyasu Suzuki have no conflicts of interest to declare in relation to this study.

\section{References}

[1] Rivers, E., Nguyen, B., Havstad, S., Ressler, J., Muzzin, A., Knoblich, B., et al. (2001) Early Goal-Directed Therapy in the Treatment of Severe Sepsis and Septic Shock. The New England Journal of Medicine, 345, 1368-1377. https://doi.org/10.1056/NEJMoa010307

[2] Giglio, M.T., Marucci, M., Testini, M. and Brienza, N. (2009) Goal-Directed Haemodynamic Therapy and Gastrointestinal Complications in Major Surgery: A Meta-Analysis of Randomized Control Trials. British Journal of Anaesthesia, 103, 637-646. https://doi.org/10.1093/bja/aep279

[3] Donati, A., Loggi, S., Preiser, J.C., Orsetti, G., Münch, C., Gabbanelli, V., et al. (2007) Goal-Directed Intraoperative Therapy Reduces Morbidity and Length of Hospital Stay in High-Risk Surgical Patients. Chest, 132, 1817-1824. https://doi.org/10.1378/chest.07-0621

[4] Pearse, R., Dawson, D., Fawcett, J., Rhodes, A., Grounds, R.M. and Bennett, E.D. (2005) Early Goal-Directed Therapy After Major Surgery Reduces Complications and Duration of Hospital Stay. A Randomised, Controlled Trial [ISRCTN38797445]. Critical Care, 9, R687-R693. https://doi.org/10.1186/cc3887

[5] Hamilton, M.A., Cecconi, M. and Rhodes, A. (2011) A Systematic Review and Meta-analysis on the Use of Preemptive Hemodynamic Intervention to Improve Postoperative Outcomes in Moderate and High-Risk Surgical Patients. Anesthesia \& Analgesia, 112, 1392-1402. https://doi.org/10.1213/ANE.0b013e3181eeaae5

[6] Lobo, D.N., Bostock, K.A., Neal, K.R., Perkins, A.C., Rowlands, B.J. and Alison, S.P. (2001) Effect of Salt and Water Balance on Recovery of Gastrointestinal Function After Elective Colonic Resection: A Randomised Controlled Trial. Lancet, 359, 1812-1818. https://doi.org/10.1016/S0140-6736(02)08711-1

[7] Cannesson, M., Musard, H., Desebbe, O., Boucau, C., Simon, R., Henaine, R., et al. (2009) The Ability of Stroke Volume Variations Obtained with Vigileo/Frotrac System to Monitor Fluid Responsiveness in Mechanically Ventilated Patients. Anesthesia \& Analgesia, 108, 513-517. https://doi.org/10.1213/ane.0b013e318192a36b

[8] Fu, Q., Mi, W.D. and Zhang, H. (2012) Stroke Volume Variation and Pleth Variability Index to Predict Fluid Responsiveness during Resection of Primary Retroperitoneal Tumors in Hans Chinese. BioScienceTrends, 6, 38-43.

[9] Manecke, G.R. (2005) Flotrac Sensor and Vigileo Monitor: Easy, Accurate, Reliable Cardiac Output Assessment Using the Arterial Pulse Wave. Expert Review of Medical Devices, 2, 523-528. https://doi.org/10.1586/17434440.2.5.523

[10] Ramsingh, D.S., Sanghvi, C., Gamboa, J., Cannesson, M. and Applegate 2nd, R.L. (2013) Outcome Impact of Goal Directed Fluid Therapy during High Risk Abdominal Surgery in Low to Moderate Risk Patients: A Randomized Controlled Trial. Journal of Clinical Monitoring and Computing, 27, 249-257. https://doi.org/10.1007/s10877-012-9422-5

[11] Scheeren, T.W., Wiesenack, C., Gerlach, H. and Marx, G. (2013) Goal-Directed Intraoperative Fluid Therapy Guided by Stroke Volume and Its Variation in High-Risk Surgical Patients: A Prospective Randomized Multicentre Study. Journal of Clinical Monitoring and Computing, 27, 225-233. https://doi.org/10.1007/s10877-013-9461-6

[12] Cannesson, M., Le Manack, Y., Hofer, C.K., Goarin, J.P., Lehot, J., Vallet, B., et al. 
(2011) Assessing the Diagnostic Accuracy of Pulse Pressure Variations for the Prediction of Fluid Responsiveness: A "Gray Zone" Approach. Anesthesiology, 115, 231-241. https://doi.org/10.1097/ALN.0b013e318225b80a

[13] Ito, M., Ito, K., Sakamoto, R., Ando, A. and Suzuki, T. (2015) Impact of Intraoperative Goal-Directed Therapy with a Fro Trac/Vigileo Sensor on Perioperative Management. Journal of Japan Society for Clinical Anesthesia, 35, 573-578. (In Japanese) https://doi.org/10.2199/jjsca.35.573

[14] Ando, A., Ito, K., Sakamoto, R., Ito, M. and Suzuki, T. (2015) The Effectiveness of Goal-Directed Therapy for Abdominal Surgery. Journal of Japan Society for Clinical Anesthesia, 35, 159-165. (In Japanese) https://doi.org/10.2199/jjsca.35.159

[15] Lilot, M., Ehrenfeld, J.M., Lee, C., Harrington, B., Cannesson, M. and Rinehart, J. (2015) Variability in Practice and Factors Predictive of Total Crystalloid Administration during Abdominal Surgery: Retrospective Two Centre Analysis. British Journal of Anaesthesia, 114, 767-776. https://doi.org/10.1093/bja/aeu452

[16] Finfer, S., Bellomo, R., Boyce, N., French, J., Myburgh, J., Norton, R., et al. (2004) A Comparison of Albumin and Saline for Fluid Resuscitation in the Intensive Care Unit. New England Journal of Medicine, 350, 2247-2256.

https://doi.org/10.1056/NEJMoa040232

[17] Japan Society of Transfusion Medicine and Cell Therapy (2015) Guidelines for Scientific Evidence-Based Proper Use of Albumin Preparations. Ministry of Health, Labour and Welfare, Tokyo. (In Japanese) http://www.mhlw.go.jp/file/05-Shingikai-11121000-Iyakushokuhinkyoku-Soumuka /0000103349.pdf

[18] Dellinger, R.P., Levy, M.M., Rhodes, A., Annane, D., Gerlach, H., Opal, S.M., et al. (2013) Surviving Sepsis Campaign: International Guidelines for Management of Severe Sepsis and Septic Shock: 2012. Critical Care Medicine, 39, 165-228. https://doi.org/10.1097/ccm.0b013e31827e83af

[19] Perner, A., Haase, N., Guttormsen, A.B., Tenhunen, J., Klemenzson, G., Åneman, A., et al. (2012) Hydroxyethyl Starch 130/0.4 versus Ringer's Acetate in Severe Sepsis. New England Journal of Medicine, 367, 124-134. https://doi.org/10.1056/NEJMoa1204242

[20] Myburgh, J.A., Finfer, S., Bellomo, R., Billot, L., Cass, A., Gattas, D., et al. (2012) Hydroxyethyl Starch or Saline for Fluid Resuscitation in Intensive Care. New England Journal of Medicine, 367, 1901-1911. https://doi.org/10.1056/NEJMoa1209759

[21] Guidet, B., Martinet, O., Boulain, T., Philippart, F., Poussel, J.F., Maizel, J., et al. (2012) Assessment of Hemodynamic Efficacy and Safety of 6\% Hydroxyethyl Starch 130/0.4 vs. $0.9 \% \mathrm{NaCl}$ Fluid Replacement in Patients with Severe Sepsis: The CRYSTMAS Study. Critical Care Medicine, 16, R94.

[22] Martin, C., Jacob, M., Vicaut, E., Guidet, B., Van Aken, H. and Kurz, A. (2013) Effect of Waxy Maize-Derived Hydroxyethyl Starch 130/0.4 on Renal Function in Surgical Patients. Anesthesiology, 118, 387-394. https://doi.org/10.1097/ALN.0b013e31827e5569

[23] Secher, N.H. (2013) When Is Enough? Individualized Goal-Directed Fluid Therapy for Surgery. Journal of Clinical Monitoring and Computing, 27, 223-224. https://doi.org/10.1007/s10877-013-9462-5

[24] Taguchi, H., Ichinose, K., Tanimoto, H., Sugita, M., Tashiro, M. and Yamamoto, T. (2011) Stroke Volume Variation Obtained with Vigileo/FloTrac ${ }^{\mathrm{TM}}$ System during Bleeding and Fluid Overload in Dogs. Journal of Anesthesia, 25, 563-568. https://doi.org/10.1007/s00540-011-1175-7 
Submit or recommend next manuscript to SCIRP and we will provide best service for you:

Accepting pre-submission inquiries through Email, Facebook, LinkedIn, Twitter, etc. A wide selection of journals (inclusive of 9 subjects, more than 200 journals)

Providing 24-hour high-quality service

User-friendly online submission system

Fair and swift peer-review system

Efficient typesetting and proofreading procedure

Display of the result of downloads and visits, as well as the number of cited articles Maximum dissemination of your research work

Submit your manuscript at: http://papersubmission.scirp.org/

Or contact ojanes@scirp.org 